\title{
A Novel Fuzzy RPID Controller for Multiarea AGC with IABC Optimization
}

\author{
Javad Javidan ${ }^{1}$ and Ali Ghasemi ${ }^{2}$ \\ ${ }^{1}$ Technical Engineering Department, University of Mohaghegh Ardabili, Ardabil 56199-11367, Iran \\ ${ }^{2}$ Electrical Engineering Department, Islamic Azad University, Ardabil, Iran
}

Correspondence should be addressed to Javad Javidan; javidan.javad@gmail.com

Received 12 December 2012; Revised 14 April 2013; Accepted 14 April 2013

Academic Editor: Mohammed Chadli

Copyright (C) 2013 J. Javidan and A. Ghasemi. This is an open access article distributed under the Creative Commons Attribution License, which permits unrestricted use, distribution, and reproduction in any medium, provided the original work is properly cited.

\begin{abstract}
An Interactive Artificial Bee Colony (IABC) Optimization based fuzzy (IABCF) to tune optimal gains of a Robust Proportional Integral Derivative (RPID) controller is proposed for the solution of multiarea automatic generation control (AGC) simulation problem in a restructured power system. One of the important problems in the proposed method is the exact tuning of the RPID parameters for achieving the desired level of robust performance. The problem of robustly tuning of RPID based AGC design is formulated as an optimization problem according to the time domain-based objective function, which is solved by the IABC technique that has a strong ability to find the most optimistic results. The robustness and effectiveness of the proffered method are shown on a two and four areas deregulated power system with possible contracted scenarios under large load demand and area disturbances in comparison with the other methods through FD and ITAE performance indices. The evaluation results show that the proposed control strategy achieves good robust performance for worldwide experience of automatic generation control in restructured systems parameters and load changes in the presence of system nonlinearities.
\end{abstract}

\section{Introduction}

Recently, the continuing growth in electricity consumption without a parallel increase in transmission has led to the subject power systems which are prevalently in process of restructuring all over the world. The base of restructuring such AGC models is to secure an open generation, consumption entities access to power transmission system, and accomplishment market relations between entities in energy market [1]. In the nominal conditions, each area is able to carry out its control incumbency, steady state corrective action of multiarea AGC, that is, confined to the area where the excess or deficit of generation occurs. The dynamic behavior of many industrial plants is influenced by disturbances and changes in the operating point. Therefore, under abnormal conditions, one or more areas may be able to correct for the generation-load mismatch due to insufficient generation reserve on AGC [2]. To achieve secure domain in the multiarea, each area participates in frequency regulation in proportion to its available regulating capacity relative to that of the overall system. In the multiarea AGC restructured power system, sake giving better condition in electricity trading and enable power exchanges was used AGC as acquires a principal and ancillary service. In the electrical market, any generation companies for power transaction have independently a contract with distribution companies. The service of control of frequency and interchange control is not provided within energy system due to technical deficiencies, but the development of AGC service market on the scale of united system is possible even now by employing AGC control ways of virtual and/or overlap area proposed herein. Such a market would allow the main producers to substantiate economically the implementation of control means and attraction of distributed resources such as controllable load [3].

The main mark of multiarea deregulation is to maintain zero steady state errors for frequency deviation and good tracking of load. On the other hand, the power system should provide the requested dispatch conditions. Multiarea AGC restructure and interconnected power systems have received 
much attention in the past decade [1-3]. The real world power system contains different kinds of uncertainties and various disturbances due to load variations, system modeling errors, and change in the power system structure. During the past decade, several proposed multiarea scenarios have been attempted to adapt traditional AGC schemes to change the environment of the power systems under deregulation [4-6].

For such problems, the classical theories were used to solve the LFC problem [6]; the conventional control strategy for the LFC problem is to take the integral of the area control error as the control signal. An integral controller provides zero steady state deviation, but it exhibits poor dynamic performance. The authors' in [5], using the robust PID controllers and the effectiveness and good performance in the $H_{\infty}$ specifications based on optimization approaches, have converted this problem to considerable attention. On the other hand, the design multiarea AGC deregulated for optimal robust PID controllers based on $H_{\infty}$ techniques results in a nonsmooth optimization problem, which suffers from computational intractability and conservatism.

In [7], the authors suggest using a particle swarm optimization (PSO) technique to tune the fuzzy PID parameters. This approach is able to improve optimization synthesis such that the global optima are guaranteed and the convergence speed of algorithm is extremely improved, too. PSO algorithm can be used to solve many of the same kinds of problems as GA and does not suffer from of GA's difficulties [8-10]. Generally, PSO is characterized as a simple concept, easy to implement, and computationally efficient. Unlike the other heuristic techniques, PSO has a flexible and well-balanced mechanism to enhance the global and local exploration abilities. However, PSO method is untoward in various operating points, for example, in the optimization of parameters of fuzzy PID $[5,7]$.

Interactive Artificial Bee Colony (IABC) Optimization may also be considered as a typical evolution and swarmbased approach for optimization, in which the search algorithm is inspired by the heuristic foraging behavior of a honeybee swarm process for finding source foods. The behavior of honeybees is the interaction of their genetic potentiality, ecological and physiological environments, and the social conditions of the colony, as well as various prior and ongoing interactions between these three parameters [6].

The paper will be arranged as follows. First, AGC in restructured power system model of the system study is presented. Second, an overview on the Interactive Artificial Bee Colony (IABC) technique is introduced. After that, the problem formulation of the optimization problem and the application of the IABC technique to such problem are presented. Finally, the simulation results of a well-known test system are introduced. The performance indices are chosen as the integral of the time multiplied absolute value of the error (ITAE) and the figure of demerit (FD) $[6,11]$.

\section{AGC in Restructured Power System}

This section gives a brief overview of automatic generation control in restructured systems. In a traditional power system structure, the generation, transmission, and distribution is owned by a single entity called "Vertically Integrated Utility" (VIU) which supplies power to the customers at regulated rates $[6,7]$. It must be noted that power system is unique from the perspective of its structure and environment; thus it requires new original and unconventional solutions for its operational control within a restructured competitive environment. The main goals of the multiarea restructure are to minimize power system frequency deviation, interchange power within the specified range, control the tie-line power flow at the scheduled value defined by the contracts among various VIUs, and maintain a generation equal to the local load. In the AGC system, this balance is achieved by detecting the frequency and tie-line power deviations to generate the ACE (area control error) signal which is in turn utilized in the integral feedback control strategy as shown in the block diagram (Figure 2 of [5]) for an $N$-area system [6].

AGC maintains the power real-time balance between power consumption and production [6]. The functioning of automatic generation control is based on the reaction to area control error (ACE) which resulted from the deviations of frequency and interchange power:

$$
\mathrm{ACE}_{i}=\Delta P_{i}+k_{s i} \times \Delta f
$$

where $\mathrm{ACE}_{i}$ is area control error of $i$ th area; $\Delta P_{i}$ is summary deviation of cross-border interchange powers of $i$ th control area; $\Delta f$ is frequency deviation; and $k_{s i}$ is factor specifying the degree of involvement of $i$ th control area in frequency control. During the operation of AGC, the error close to zero is maintained in all areas. In a competitive market structure, VIUs no longer exist. The utilities do not own generation transmission-distribution in one system; instead there are three different entities, namely, GENCOs (generation companies), TRANSCOs (transmission companies), and DISCOs (distribution companies). According to the proposed idea in [10], the significant of an "Augmented Generation Participation Matrix" (AGPM) to express the possible contracts following is presented here. The AGPM shows the communion factor of a GENCO in the load following contract with a DISCO [6]:

$$
\begin{gathered}
\mathrm{AGPM}=\left[\begin{array}{ccc}
\operatorname{AGPM}_{11} & \cdots & \mathrm{AGPM}_{1 N} \\
\vdots & \ddots & \vdots \\
\operatorname{AGPM}_{N 1} & \cdots & \mathrm{AGPM}_{N N}
\end{array}\right], \\
\operatorname{AGPM}_{i j}=\left[\begin{array}{ccc}
\operatorname{gpf}_{\left(s_{i}+1\right)\left(z_{j}+1\right)} & \cdots & \operatorname{gpf}_{\left(s_{i}+1\right)\left(z_{j}+m_{j}\right)} \\
\vdots & \ddots & \vdots \\
\operatorname{gpf}_{\left(s_{i}+n_{i}\right)\left(z_{j}+1\right)} & \cdots & \operatorname{gpf}_{\left(s_{i}+n_{i}\right)\left(z_{j}+m_{j}\right)}
\end{array}\right] \\
\text { for } i, j=1, \ldots, N, s_{i}=\sum_{k=1}^{i-1} n_{i}, \\
z_{j}=\sum_{k=1}^{j-1} m_{j}, \quad s_{1}=z_{1}=0
\end{gathered}
$$

where $n_{i}$ and $m_{i}$ define the number of GENCOs and DISCOs in area $i$ and gpf $_{i j}$ refers to "generation participation factor" 
and displays the participation factor GENCO $i$ in total load following requirement of DISCO $j$ based on the possible contracts. The sum of all inputs in each column of AGPM is univalent. According to $[6,7]$, we can write the below formulations in multiarea restructure:

$$
\begin{gathered}
\sum_{j=1}^{n_{i}} \mathrm{apf}_{j i}=1, \quad d_{i}=\Delta P_{\mathrm{Loc}, j}+\Delta P_{d i}, \\
\Delta P_{\mathrm{Loc}, j}=\sum_{j=1}^{m_{i}} \Delta P_{L j-i}, \quad \Delta P_{d i}=\sum_{j=1}^{m_{i}} \Delta P_{U L j-i}, \\
\eta_{i}=\sum_{j=1, j \neq i}^{N} T_{i j} \Delta f_{j}, \quad \xi_{i}=\Delta P_{\mathrm{tie}, i, \mathrm{sch}} \sum_{k=1, k \neq i}^{N} \Delta P_{\mathrm{tie}, i k, \mathrm{sch}}, \\
\Delta P_{\mathrm{tie}, i k, \mathrm{sch}}=\sum_{j=1}^{n_{l}} \sum_{i=1}^{m_{k}} \mathrm{apf}_{\left(s_{l}+j\right)\left(z_{k}+i\right)} \Delta P_{L\left(z_{k}+i\right)-k} \\
\rho_{i}=\left[\sum_{i=1}^{n_{k}} \sum_{j=1}^{m_{i}} \mathrm{apf}_{\left(s_{k}+i\right)\left(z_{l}+j\right)} \Delta P_{L\left(z_{l}+j\right)-l},\right. \\
\rho_{k i}=\sum_{j=1}^{N}\left[\sum_{t=1}^{m_{j}} \operatorname{gpf}_{\left(s_{i}+k\right)\left(z_{j}+t\right)} \Delta P_{L t-j}\right], \\
\Delta P_{m, k-i}=\rho_{k i}+\operatorname{apf}_{k i} \Delta P_{d i}, \quad k=1,2, \ldots, n_{i},
\end{gathered}
$$

where $\Delta P_{m, k i}$ is the desired total power generation of a GENCO $k$ in area $i$ and must track the demand of the DISCOs in contract with it in the steady state. The used nomenclature is given in Nomenclature section.

The actual and scheduled steady state power flows on the tie line are given as equations in [5].

It is possible to have various combinations of contracts between DISCOs and GENCOs which can be conveniently visualized by the concept of a "DISCO Participation Matrix" (DPM). Essentially, DPM gives the participation of a DISCO in contract with a GENCO. The rows of a DPM correspond to GENCOs and columns to DISCOs which contract power. Each entry in this matrix can be thought as a fraction of a total load contracted by a DISCO (column) towards a GENCO (row). Any entry of this matrix is a function of total load power contracted by a DISCO toward a GENCO. As a result, the total of entries of column belong to $\mathrm{DISCO}_{i}$ of DPM is $\sum_{i} \mathrm{cpf}_{i j}=1$. The corresponding DPM to the considered power system having two areas with each of them including two DISCOs and two GENCOs is given in (4) $[12,13]$, where cpf represents "contract participation factor" and is like signals that carry information as to which GENCO has to follow load demanded by which DISCO. The DPM for four-area system can be derived $[6,7,12]$ by the similar way in (10) for two areas:

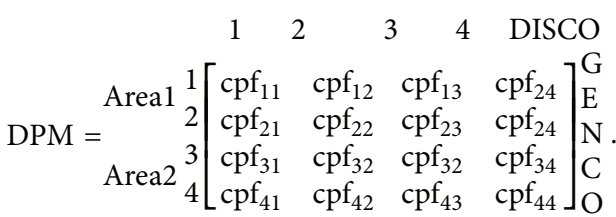

\section{Interactive Artificial Bee Colony (IABC)}

3.1. Artificial Bee Colony ( $A B C)$. In this section, we introduce $\mathrm{ABC}$ algorithm. One of the most recently defined algorithms based on the foraging behavior of the honeybees for numerical optimization problems is Artificial Bee Colony by Karaboga [14] in 2005. The extended version of the $\mathrm{ABC}$ algorithm for the constrained optimization problems was carried out in [15]. In fact, the above algorithm is a combination of the differential evolution (DE) and the particle swarm optimization (PSO), which employs common control parameters such as colony size and maximum cycle number. In the Artificial Bee Colony, the foraging bees are classified into three categories scout bees, employed bees and onlookers, among which the number of onlooker bees and that of employed bees (BN) are equal. All bees that are currently exploiting a food source are known as employed. The task of employed bees is to carry the information about food source, exploit the food source, and share this information with onlooker bees. Onlooker bees are waiting in the hive for the information to be shared by the employed bees about their discovered food sources [16]. Onlooker bees watch the dance and choose a food source according to the probability proportional to the quality of that food source. So to conclude, the $\mathrm{ABC}$ techniques are used by employed and onlooker bees to find and choose best food sources with fly around in a multidimensional search space [11]. This goal depends on three conditions, such as, adjusting their positions, their nest mates, and experience of themselves. The process of the $\mathrm{ABC}$ algorithm is presented as follows [17].

Step 1 (initialization). Generate random population and calculate their fitness values. This population and fitness values are called employed bees and nectar amounts, respectively.

Step 2 (move the onlookers). An onlooker bee evaluates the nectar information taken from all employed bees and chooses a food source with a probability related to its nectar amount by (5); this method is known as roulette wheel selection method. One has

$$
p_{i}=\frac{\text { fit }_{i}}{\sum_{n=1}^{\mathrm{SN}} \mathrm{fit}_{i}},
$$

where $p_{i}$ and $\mathrm{SN}$ are probability of selecting the $i$ th employed bee and number of employed bees, respectively, and fit ${ }_{i}$ is the fitness value of the solution. The movement of the onlookers follows

$$
x_{i j}(t+1)=\theta_{i j}+\varphi\left(\theta_{i j}(t)-\theta_{k j}(t)\right),
$$

where $k \in\{1,2, \ldots, \mathrm{BN}\}$ and $j \in\{1,2, \ldots, D\}$ are randomly chosen indices and $x_{i}, t, \theta_{k}$, and $\phi()$ are the position of the $i$ th onlooker bee, the iteration number, the randomly chosen employed bee, and random variable in the range $[-1,1]$, respectively. $D$ is the number of dimension of optimization problem.

Step 3 (move the scouts). When selecting a food source, all the employed bees associated with it abandon 


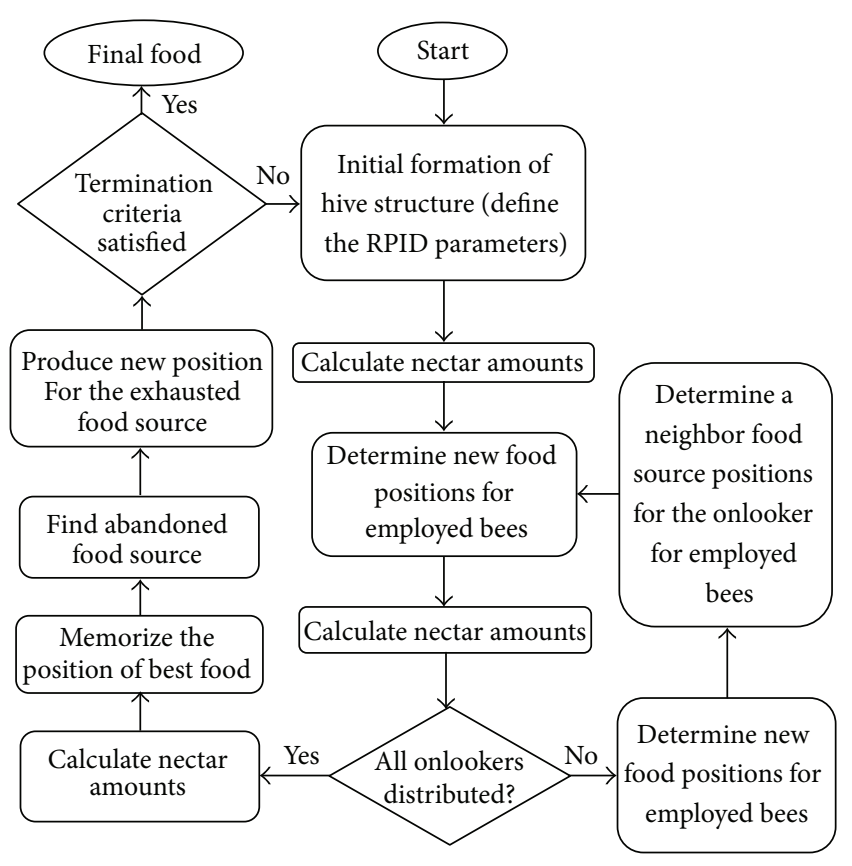

FIGURE 1: Algorithm and computational flowchart of IABC.

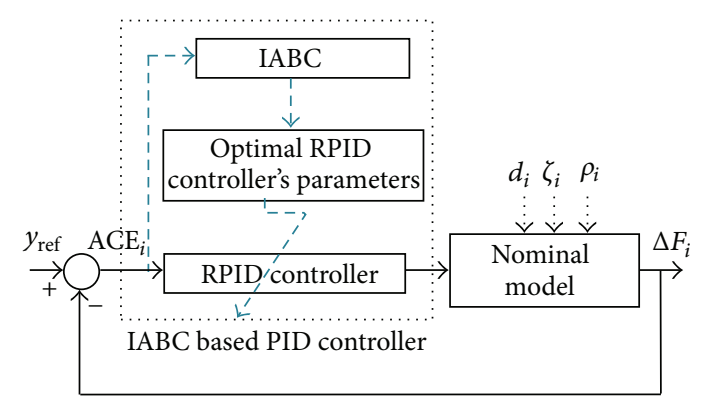

FIGURE 2: The introduced IABC based RPID controller structure.

the food source and become scout. The scouts are moved by

$$
\theta_{i j}=\theta_{i j_{\min }}+r \cdot\left(\theta_{i j_{\max }}-\theta_{i j_{\min }}\right),
$$

where $r$ is a random factor and $r \in[0,1]$.

Step 4 (update the best food source found so far). Memorize the best food source found so far.

Step 5 (termination checking). Checking termination criteria satisfied; if it is satisfied then stop algorithm, otherwise go to Step 2.

3.2. Interactive Artificial Bee Colony (IABC). Although, the supposed algorithm is prosperous for finding best answer in optimization problem, it considers the relation of employed bee and is selected by the roulette wheel selection [17]. The factor of this mathematics formulation is random. Hence, it cannot use full exploitation capacity. In order to overcome this drawback, the Newtonian law of universal gravitation is

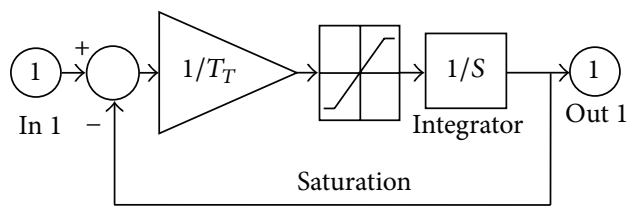

FIgURE 3: Nonlinear turbine model with GRC.

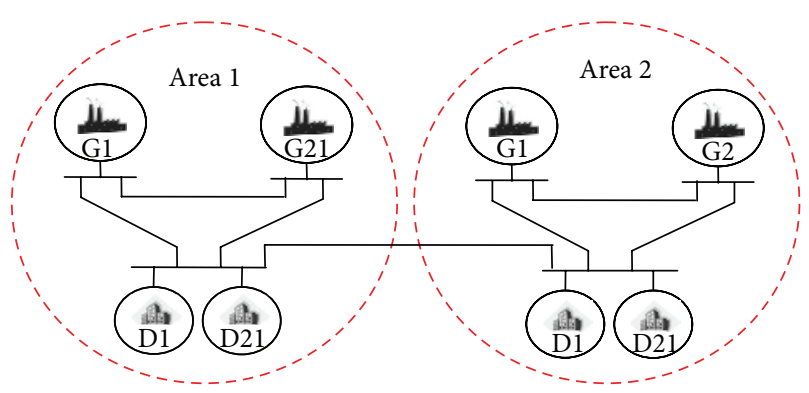

FIGURE 4: A two-area restructured power system.

used $[18,19]$. The Interactive Artificial Bee Colony (IABC) algorithm used (8); the universal gravitations between the selected employed bees are exploited by the roulette wheel selection and the onlooker bee. One has

$$
F_{12}=G \frac{m_{1} m_{2}}{r_{21}^{2}} \widehat{r}_{21}, \quad \widehat{r}_{21}=\frac{r_{2}-r_{1}}{\left|r_{2}-r_{1}\right|},
$$

where $m_{1}, m_{2}, r_{21}, \widehat{r}_{21}, F_{12}$, and $G$ are masses of the objects, the separation between the objects, the unit vector defined with (9), the gravitational force heads from the object 1 to the object 2, and the universal gravitational constant, respectively. In the supposed algorithm, the masses $m_{1}$ and $m_{2}$ are replaced by the parameters $F\left(\theta_{i}\right)$ and $F\left(\theta_{k}\right)$, they are fitness values of the employed bee picked by applying the roulette wheel selection and of the randomly selected employed bee, respectively [17]. We can drive similar formulation for universal gravitation. Therefore, it can be written as

$$
\begin{gathered}
F_{i k_{j}}=G \frac{F\left(\theta_{i}\right) \times F\left(\theta_{k}\right)}{\left(\theta_{k j}-\theta_{i j}\right)^{2}} \cdot \frac{\theta_{k j}-\theta_{i j}}{\left|\theta_{k j}-\theta_{i j}\right|}, \\
x_{i j}(t+1)=\theta_{i j}(t)+F_{i k_{j}} \cdot\left[\theta_{i j}(t)-\theta_{k j}(t)\right],
\end{gathered}
$$

where $F_{i k} \cdot\left[\theta_{i}-\theta_{k}\right]$ is considered universal gravitation between the employed bee which is hand-picked by the onlooker bee, and more than one employed bees [17]. $F_{i k}$ plays factor controlling in the roulette wheel selection [18]. By developing and considering the gravitation between the picked employed bee and $n$ selected employed bees, the results can be written with

$$
x_{i j}(t+1)=\theta_{i j}(t)+\sum_{k=1}^{n} \widetilde{F}_{i k_{j}} \cdot\left[\theta_{i j}(t)-\theta_{k j}(t)\right],
$$

where $\widetilde{F}_{i k_{j}}$ is the normalized gravitation. In general, the whole process of IABC algorithm can be summarized at five main steps as follows [11]. 

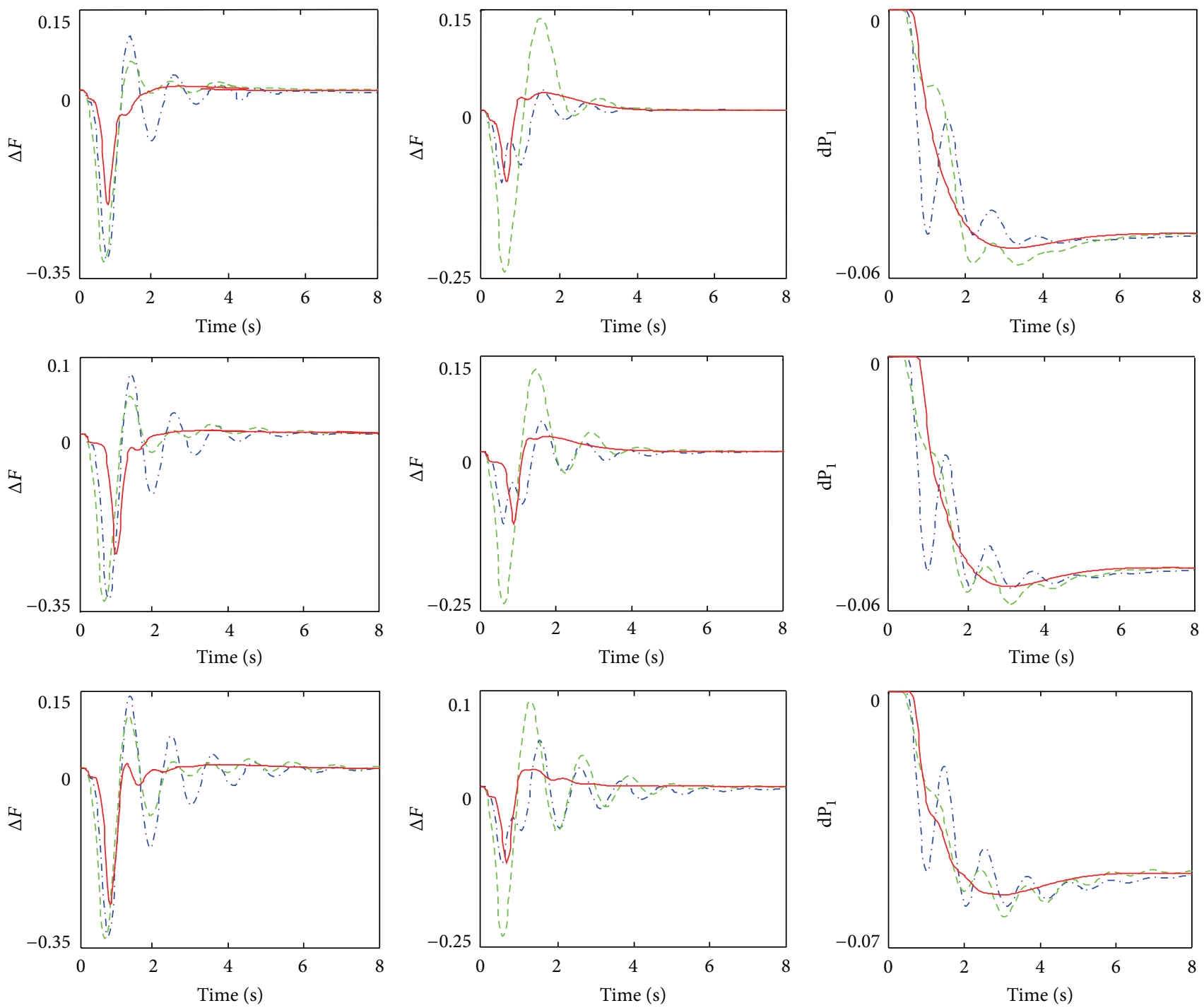

FIGURE 5: Deviation of frequency and tie-line power flows; solid (IABC-F), dashed (PSO-F), and dashed dotted (GA-F).

Step 1 (initialization).

Step 2 (move the onlookers).

Step 3 (move the scouts).

Step 4 (update the best food source found so far).

Step 5 (termination checking).

Also, the Algorithm and computational flowchart of IABC method to optimize the RPID parameters is presented in Figure 1.

\section{IABC-Based RPID Type Load Frequency Controller}

In this paper, an IABC fuzzy based on RPID is proposed, which combines the advantage of the IABC and fuzzy control techniques to achieve good robust performance. In addition, robust PID controller is used for the solution of multiarea restructure problem. On the other hand, their robustness and reliability make fuzzy controllers useful to solve a wide range of control problems in power systems. Fuzzy logic control is one of the most successful areas in the application of fuzzy theory and is excellent alternative to the conventional control methodology when the processes are too complex to be analyzed by conventional mathematical techniques [6, 20-23].

The robust PID controller shows good performance in wide range of operating conditions and it is easy to implement using analogue or digital hardware and familiar to engineers; it depends on the optimal tuning of the PID controller's parameters. In order to overcome these backwashes and supply optimal control performance, IABC algorithm is proposed to optimal tune of PID controllers parameters under different operating conditions. Figure 2 shows the block diagram of IABC algorithm based tuned PID controller to solve the multiarea restructure problem for each control area in both case studies [6]. Also the equation of load 


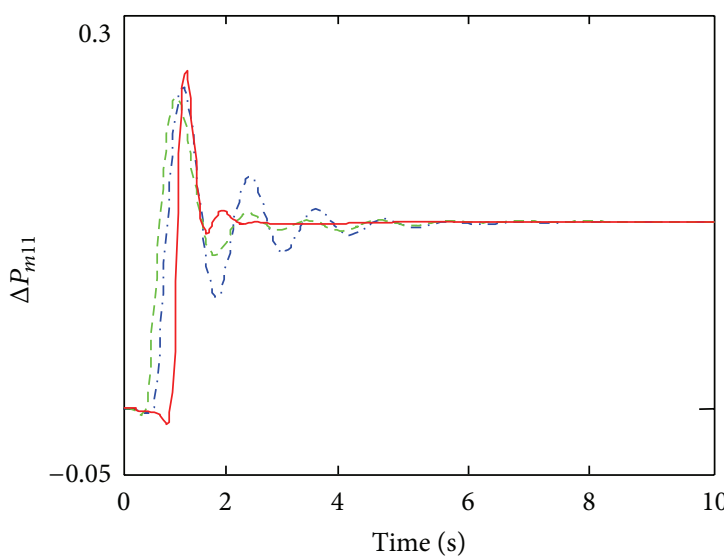

(a)

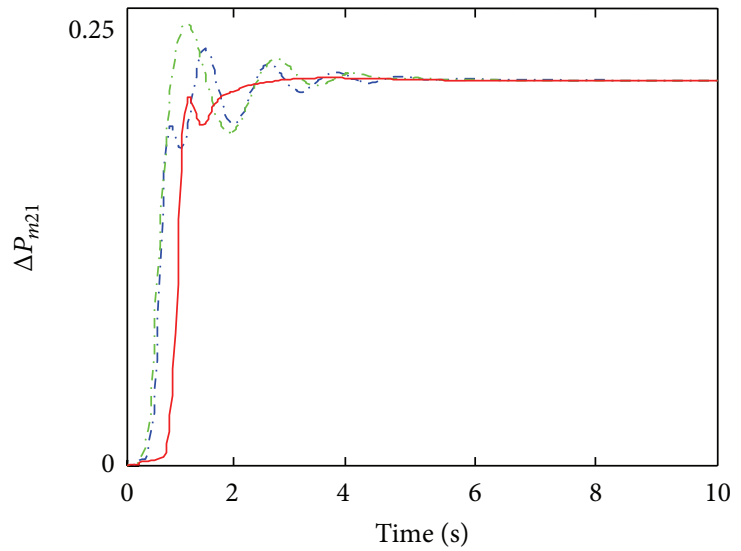

(c)

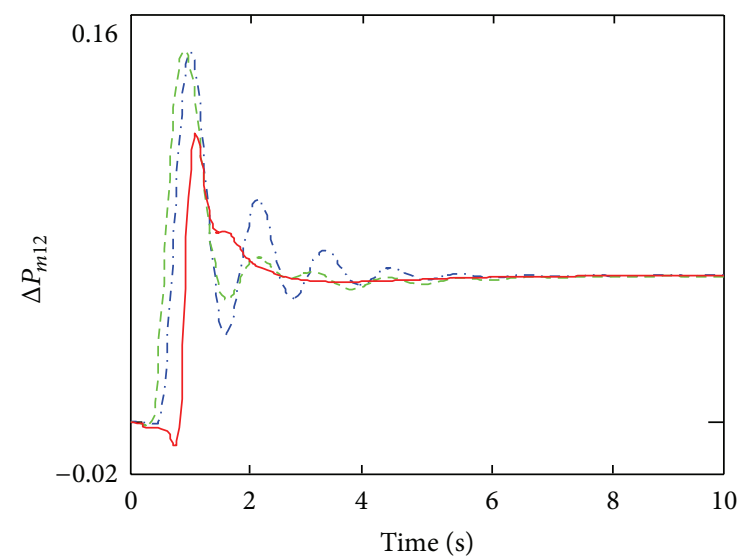

(b)

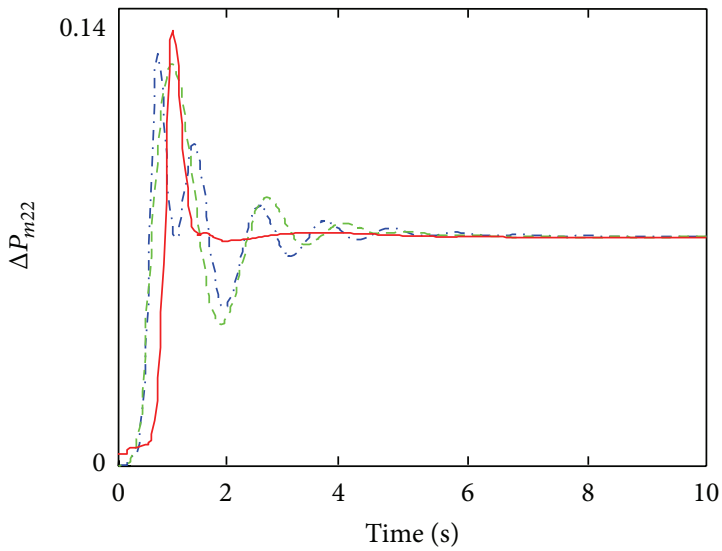

(d)

FIGURE 6: Power after any GENCO in nominal load; Solid (IABC-F), Dashed (PSO-F), and Dashed Dotted (GA-F).

frequency control for PID in each control area (in both case studies) is

$$
\mathrm{PID}=k_{P}+\frac{k_{I}}{s}+k_{D} s
$$

The above equation is ideal design of PID controller but it is impossible. There is no doubt that in industrial PID controller, using low pass filter is necessary to omit high frequency noise in entry of differentiator. Therefore in this paper for PID controller, conversion function of differentiator is

$$
\frac{k_{D}}{1+T_{d} S}, \quad T_{d}=100, \text { where } k_{D} \leq T .
$$

It should be noted that the choice of the properly objective function is very important in the synthesis procedure for achieving the desired level of system robust performance.

For our optimization problem, an integral of the time multiplied absolute value of the error (ITAE) is taken as the objective function [24]. The objective function is defined as follows:

$$
\begin{aligned}
& K_{P i}^{\min } \leq K_{P i} \leq K_{P i}^{\max }, \\
& K_{I i}^{\min } \leq K_{I i} \leq K_{I i}^{\max }, \\
& K_{D i}^{\min } \leq K_{D i} \leq K_{D i}^{\max } .
\end{aligned}
$$

Typical ranges of the optimized parameters are [0.01-20]. One has

$$
\begin{gathered}
J=\operatorname{Max}\left\{\operatorname{ITAE}^{p=-30 \%}, \operatorname{ITAE}^{p=-20 \%}, \ldots, \operatorname{ITAE}^{p=+30 \%}\right\}, \\
\operatorname{ITAE}^{p}=\sum_{i=1}^{N} \int_{0}^{t=t_{\text {sim }}} t\left|\mathrm{ACE}_{i}\right| d t,
\end{gathered}
$$

where $t_{\text {sim }}$ is the range of simulation time, $N$ is the number of area control in power systems, and $p$ is the percent value of the uncertain plant parameters from the nominal values for which the optimization is carried out. The operating conditions are considered with variation uncertain plant parameters of $K_{p i}, T_{p i}, B_{i}, R_{i}$, and $T_{i j}$ from $-30 \%$ to $30 \%$ of the nominal values by $10 \%$ step (i.e., 7 operating points) [24].

\section{Simulation Results}

By way of illustration, two cases were considered in simulation: two- and four-area restructure with possible contracted scenarios under large load demand and area disturbances in comparison.

Case 1. The first study is two-area restructure. In the simulation study, a nonlinear model of Figure 3 with \pm 0.1 replaces 
TABLE 1: ITAE and FD performance indices for Case 1.

\begin{tabular}{|c|c|c|c|c|c|c|}
\hline \multirow{2}{*}{ Change of parameters } & \multicolumn{2}{|c|}{ IABC-FPID } & \multicolumn{2}{|c|}{ PSO-FPID } & \multicolumn{2}{|c|}{ GA-FPID } \\
\hline & ITAE & FD & ITAE & FD & ITAE & FD \\
\hline $25 \%$ & 0.175 & 4.347 & 0.387 & 57.943 & 0.554 & 124.838 \\
\hline $20 \%$ & 0.176 & 4.366 & 0.404 & 62.682 & 0.571 & 131.142 \\
\hline $15 \%$ & 0.186 & 4.513 & 0.423 & 68.020 & 0.588 & 138.122 \\
\hline $10 \%$ & 0.182 & 4.581 & 0.443 & 74.032 & 0.605 & 145.601 \\
\hline $5 \%$ & 0.180 & 4.632 & 0.464 & 80.430 & 0.625 & 153.825 \\
\hline Nominal & 0.176 & 4.60 & 0.484 & 87.795 & 0.647 & 162.919 \\
\hline$-5 \%$ & 0.205 & 5.085 & 0.506 & 95.854 & 0.671 & 173.010 \\
\hline$-10 \%$ & 0.181 & 4.730 & 0.527 & 105.787 & 0.740 & 184.776 \\
\hline$-15 \%$ & 0.163 & 4.633 & 0.559 & 118.408 & 0.737 & 196.615 \\
\hline$-20 \%$ & 0.181 & 4.964 & 0.605 & 130.338 & 0.816 & 211.230 \\
\hline$-25 \%$ & 0.166 & 4.844 & 0.670 & 146.116 & 0.853 & 226.947 \\
\hline
\end{tabular}

TABLE 2: PID controller gains of Case 1.

\begin{tabular}{lcccccc}
\hline Algorithm & $K_{p 1}$ & $K_{i 1}$ & $K_{d 1}$ & $K_{p 2}$ & $K_{i 2}$ & $K_{d 2}$ \\
\hline GA & 1.177 & 1.052 & 0.223 & 1.079 & 0.569 & 1.103 \\
PSO & 0.88 & 2.05 & 0.28 & 0.01 & 0.69 & 0.16 \\
IABC & 2.786 & 2.231 & 1.4567 & 1.9801 & 3.7821 & 1.026 \\
\hline
\end{tabular}

the linear model of turbine $\Delta P V_{k i} / \Delta P T_{k i}$ in Figure 2 of [5]. This is to take GRC into account, that is, the practical limit on the rate of the change in the generating power of each GENCO. The proposed RPID controller based on IABC is applied for each control area of the restructured power system to explain its robustness against parametric uncertainties and contract variations. A two-area power system was shown in Figure 4 [6].

For this purpose the elements of DPM matrixes is $\mathrm{cpf}_{i j}$ and the factor for restructured system as

$$
\mathrm{DPM}=\left[\begin{array}{llll}
0.5 & 0.25 & 0.0 & 0.3 \\
0.2 & 0.25 & 0.0 & 0.0 \\
0.0 & 0.25 & 1.0 & 0.7 \\
0.3 & 0.25 & 0.0 & 0.0
\end{array}\right]
$$

The results of the proposed controller based on the IABC algorithm are compared with the PSO-F PID [7] and GAF PID [21]. Also, disturbance for the area is $\mathrm{dP}_{1}=0.05$ and $\mathrm{dP}_{2}=0.03$. The modifications of excess power in this scenario can be considered as Discol $=0.17$ is equal to 0.1 +0.07 , Disco $2=0.14$ is equal to $0.1+0.04$, Disco3 $=0.12$ is equal to $0.1+0.02$, and Disco $4=0.12$ is equal to $0.1+$ 0.02 . In addition, the factors of PID controller are $\operatorname{apf}_{1}=0.75$, $\operatorname{apf}_{2}=1-\operatorname{apf}_{1}, \operatorname{apf}_{3}=0.5$, and $\operatorname{apf}_{4}=1-\operatorname{apf}_{3}$. The simulation results for $+25 \%, 0 \%$, and $-25 \%$ change of parameters of LFC are illustrated in Figures 5 and 6 [6]. In the optimization problem, performance indices such as ITAE based on $\mathrm{ACE}_{i}$ and FD based on system responses characteristic are defined as

$$
\begin{gathered}
\mathrm{ITAE}=\int_{0}^{t_{\text {sim }}}\left(\left|\mathrm{ACE}_{i}(t)\right|\right) d t, \\
\mathrm{FD}=(\mathrm{OS} \times 70)^{2}+(\mathrm{US} \times 5)^{2}+\left(T_{S}\right)^{2} .
\end{gathered}
$$

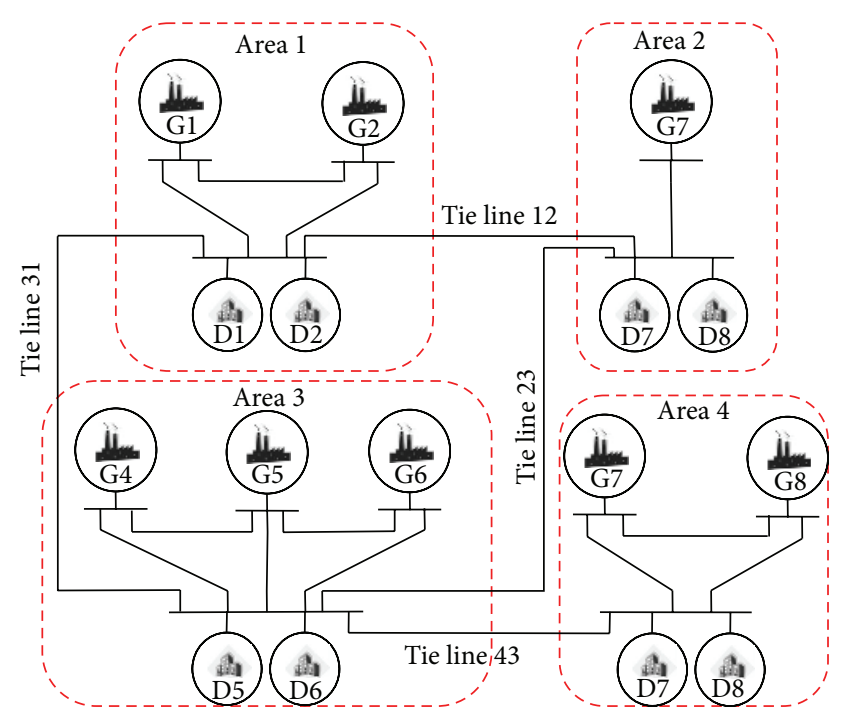

FIGURE 7: Schematic diagram of a four-area system in restructured power market for Case 2 .

In the above equation, OS, US, and $T_{S}$ are overshoot, undershoot and settling time, respectively. The evaluation of the FD considers for $2 \%$ of the band of the total load demand in area 1. The numerical results of ITAE and FD for Case 1 are demonstrated in Table 1.

The optimized parameters of PID controller and data of controller area and GENCOs are presented in Tables 2 and 3, respectively. In addition, the disturbance of the area is: $\mathrm{dP}_{1}=$ $5 \%, \mathrm{dP}_{2}=3 \%$.

Case 2. In this case, we study two scenarios.

Scenario I. In order to carry out this scenario we make some assumption. The basic assumption of this method is about the DPM matrix where all the DISCOs contract with the GENCOs for power per the DPM (18) [5]. 
TABLE 3: Data of controller area and GENCOs.

\begin{tabular}{lcccccc}
\hline \multirow{2}{*}{ Parameter } & \multirow{2}{*}{ Area 1} & \multirow{2}{*}{ Area 2} & \multicolumn{3}{c}{ MVA $_{\text {base }}$} & \multicolumn{3}{c}{ GENCOs $(k$ in area $i)$} \\
& & & $(1000 \mathrm{MW})$ parameter & $1-1$ & $2-1$ & $1-2$ \\
\hline$K_{P}(\mathrm{~Hz} / \mathrm{pu})$ & 120 & 120 & Rate $(\mathrm{MW})$ & 800 & 1000 & 1100 \\
$T_{P}(\mathrm{sec})$ & 20 & 20 & $T_{T}(\mathrm{sec})$ & 0.3 & 0.30 & 0.30 \\
$B(\mathrm{pu} / \mathrm{Hz})$ & 0.425 & 0.425 & $T_{T}(\mathrm{sec})$ & & 0.10 & 0.10 \\
$T_{i j}(\mathrm{pu} / \mathrm{Hz})$ & \multicolumn{2}{c}{$T_{12}=0.545$} & $\alpha(\mathrm{Hz} / \mathrm{pu})$ & 2.4 & 2.4 & 0.30 \\
& & & $\alpha$ & 1 & 1 & 1 \\
\hline
\end{tabular}

TABLE 4: The optimized parameters of PID controller.

\begin{tabular}{|c|c|c|c|c|}
\hline \multirow{2}{*}{ Technique } & \multicolumn{4}{|c|}{ Optimal PID gains } \\
\hline & Area 1 & Area 2 & Area 3 & Area 4 \\
\hline \multicolumn{5}{|c|}{$T_{p 1}=10.0, B_{1}=0.125, T_{12}=0.145, T_{13}=0.145$} \\
\hline \multicolumn{5}{|c|}{ Serial number 1 of scenario I from Case 2} \\
\hline \multicolumn{5}{|c|}{ ( } \\
\hline$K_{p}$ & 1.1335 & 1.0000 & 1.0000 & 1.0000 \\
\hline$K_{i}$ & 1.5820 & 1.0000 & 1.1746 & 1.7914 \\
\hline$K_{d}$ & 2.0000 & 1.7537 & 1.9844 & 1.7491 \\
\hline \multicolumn{5}{|l|}{ RGA } \\
\hline$K_{p}$ & 1.110 & 1.0958 & 1.0000 & 1.1000 \\
\hline$K_{i}$ & 0.5328 & 0.5600 & 0.5430 & 0.5423 \\
\hline$K_{d}$ & 2.0000 & 2.0000 & 2.0000 & 2.0000 \\
\hline \multicolumn{5}{|l|}{ HPSOCFA } \\
\hline$K_{p}$ & 1.0000 & 2.0000 & 1.0000 & 1.0000 \\
\hline$K_{i}$ & 1.0000 & 1.0000 & 2.0000 & 1.0000 \\
\hline$K_{d}$ & 2.0000 & 2.0000 & 2.0000 & 1.0000 \\
\hline \multicolumn{5}{|l|}{$\mathrm{IABC}$} \\
\hline$K_{p}$ & 0.9876 & 1.2341 & 1.0453 & 1.3230 \\
\hline$K_{i}$ & 0.3754 & 0.4532 & 0.4308 & 0.4987 \\
\hline$K_{d}$ & 2.8765 & 2.9973 & 2.0000 & 2.8970 \\
\hline \multicolumn{5}{|c|}{$\begin{array}{c}T_{p 1}=10.0, B_{1}=0.125, T_{12}=0.145, T_{13}=0.345 \\
\text { Serial number } 2 \text { of scenario I from Case } 2\end{array}$} \\
\hline \multicolumn{5}{|c|}{ ( } \\
\hline$K_{p}$ & 1.0000 & 1.7302 & 1.3716 & 1.0000 \\
\hline$K_{i}$ & 1.0000 & 1.0000 & 1.7051 & 1.0000 \\
\hline$K_{d}$ & 2.0000 & 1.9639 & 1.8914 & 1.6563 \\
\hline \multicolumn{5}{|l|}{ RGA } \\
\hline$K_{p}$ & 1.1125 & 1.0385 & 1.1000 & 1.0183 \\
\hline$K_{i}$ & 0.5423 & 0.5700 & 0.5530 & 0.5748 \\
\hline$K_{d}$ & 2.0000 & 2.0000 & 2.0000 & 2.0000 \\
\hline \multicolumn{5}{|l|}{ HPSOCFA } \\
\hline$K_{p}$ & 1.0000 & 1.1621 & 1.0000 & 2.0000 \\
\hline$K_{i}$ & 2.0000 & 2.0000 & 2.0000 & 2.0000 \\
\hline$K_{d}$ & 1.0000 & 1.7302 & 1.3716 & 1.0000 \\
\hline \multicolumn{5}{|l|}{ IABC } \\
\hline$K_{p}$ & 1.8421 & 1.9398 & 1.8435 & 1.7233 \\
\hline$K_{i}$ & 0.3754 & 0.3532 & 0.3642 & 0.3532 \\
\hline$K_{d}$ & 3.9341 & 3.6784 & 3.9553 & 3.9567 \\
\hline
\end{tabular}

The GENCO participating in AGC is defined by the following apfs:

Area 1: $\operatorname{apf}_{1}=0.5, \operatorname{apf}_{2}=0.5$,
Area 2: $\operatorname{apf}_{3}=1.0$,

$$
\mathrm{DPM}=\left[\begin{array}{llllllll}
0.50 & 0.50 & 0.00 & 0.00 & 0.00 & 0.00 & 0.00 & 0.00 \\
0.50 & 0.50 & 0.00 & 0.00 & 0.00 & 0.00 & 0.00 & 0.00 \\
0.00 & 0.00 & 1.00 & 1.00 & 0.00 & 0.00 & 0.00 & 0.00 \\
0.00 & 0.00 & 0.00 & 0.00 & 0.30 & 0.25 & 0.00 & 0.00 \\
0.00 & 0.00 & 0.00 & 0.00 & 0.40 & 0.50 & 0.00 & 0.00 \\
0.00 & 0.00 & 0.00 & 0.00 & 0.30 & 0.25 & 0.00 & 0.00 \\
0.00 & 0.00 & 0.00 & 0.00 & 0.00 & 0.00 & 0.50 & 0.60 \\
0.00 & 0.00 & 0.00 & 0.00 & 0.00 & 0.00 & 0.50 & 0.40
\end{array}\right],
$$

Area 3: $\operatorname{apf}_{4}=1 / 3, \operatorname{apf}_{5}=1 / 3$, and $\operatorname{apf}_{6}=1 / 3$,

Area 4: $\operatorname{apf}_{7}=0.5, \operatorname{apf}_{8}=0.5$.

The scheduled load of DISCOs in different areas is defined as follows:

$$
\begin{aligned}
& \text { delPdisco } 1=0.3, \text { delPdisco } 2=0.2, \text { delPdisco } 3=0.1, \\
& \text { delPdisco } 4=0.4, \text { delPdisco } 5=0.3, \text { delPdisco } 6=0.3, \\
& \text { delPdisco } 7=0.3, \text { delPdisco } 8=0.2 .
\end{aligned}
$$

The local loads of areas 1, 2, 3, and 4 are:

delPuncot $1=0.15$, delPuncot $2=0.15$, delPuncot $3=0.2$, and delPuncot $4=0.2$, respectively.

The ratio of rated power in four-area restructure is as follows:

$$
\begin{gathered}
\alpha_{12}=2.5, \quad \alpha_{23}=\frac{1}{3}, \quad \alpha_{31}=1.2, \\
\alpha_{24}=0.5, \quad \alpha_{43}=\frac{1}{1.5},
\end{gathered}
$$

where, $\alpha_{i, j}$ is the ratio of rated power between area $i$ and area j.

Based on all abovementioned ideas, a block diagram for an AGC in a deregulated system can be conceptualized and depicted in Figure 7. The other data of four-area restructure is provided in Table 7.

The optimized parameters of PID controller are listed in Table 4, and the numerical results of ITAE and FD for Case 1 are reported for serial numbers 1 and 2 in Tables 5 and 6, respectively. In addition, in scenario I of Case 2 considered two simulation or serial numbers. The results are compared with two indices ITAE and FD according to (20) and (21), respectively. The results of the proposed controller based 


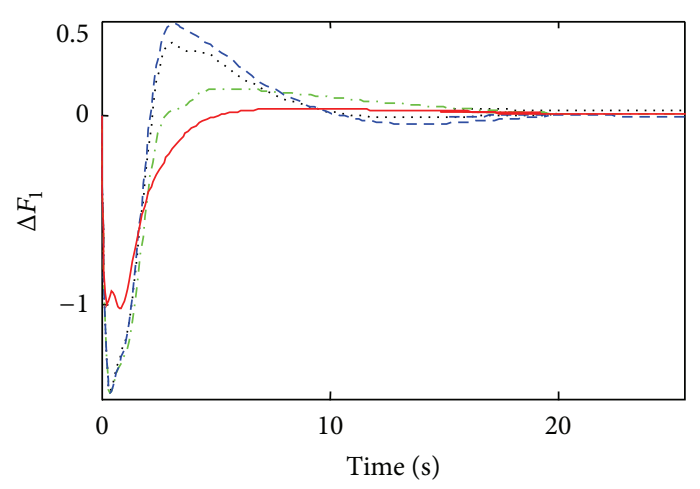

(a)

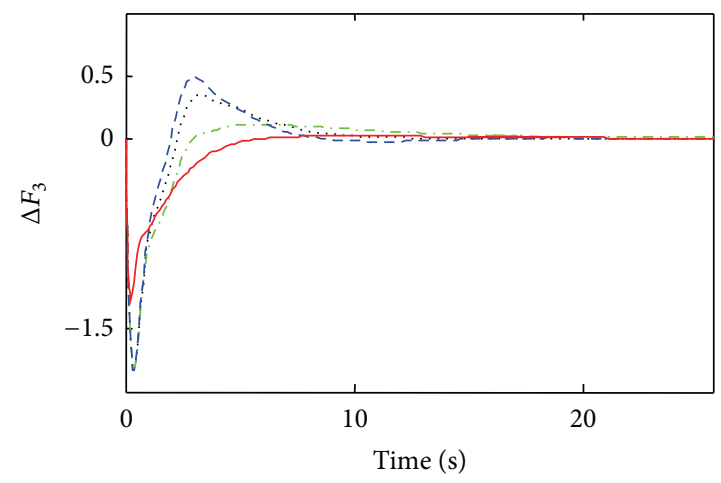

(c)

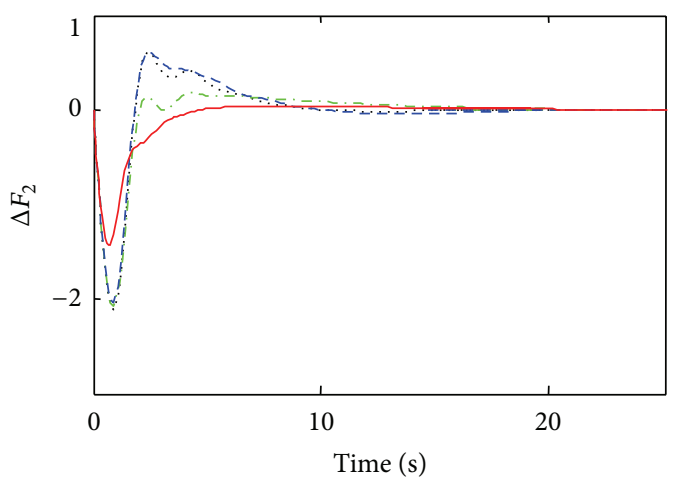

(b)

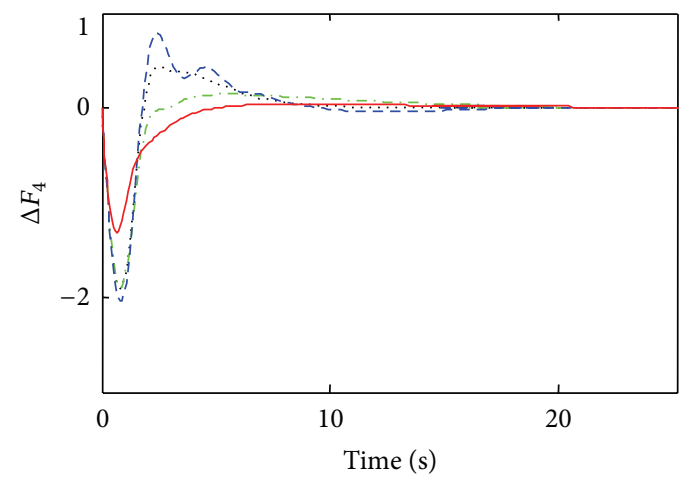

(d)

FIGURE 8: Deviation of frequency; (a) area 1, (b) area 2, (c) area 3, and (d) area 4 for $+25 \%$ change of parameters; solid (IABC), dashed (HPSOCFA), dashed dotted (RGA), and dotted (BGA).

TABLE 5: ITAE and FD in serial number 1 for scenario I in Case 2.

\begin{tabular}{|c|c|c|c|c|c|c|c|c|}
\hline \multirow{2}{*}{ Change of parameters } & \multicolumn{2}{|c|}{ HBMO } & \multicolumn{2}{|c|}{ HPSOCFA } & \multicolumn{2}{|c|}{ RGA } & \multicolumn{2}{|c|}{ BGA } \\
\hline & ITAE & $\mathrm{FD}$ & ITAE & FD & ITAE & $\mathrm{FD}$ & ITAE & FD \\
\hline $25 \%$ & 4.918 & 1.835 & 5.485 & 6.153 & 5.474 & 2.803 & 3.983 & 4.488 \\
\hline $20 \%$ & 4.552 & 1.856 & 5.488 & 6.167 & 5.293 & 2.725 & 3.984 & 4.560 \\
\hline $15 \%$ & 4.130 & 1.886 & 5.447 & 6.231 & 5.121 & 2.661 & 3.979 & 4.660 \\
\hline $10 \%$ & 3.645 & 1.913 & 5.394 & 6.308 & 4.900 & 2.634 & 3.964 & 4.795 \\
\hline $5 \%$ & 3.072 & 1.934 & 5.319 & 6.417 & 4.633 & 2.538 & 3.938 & 4.957 \\
\hline Nominal & 2.484 & 1.987 & 5.222 & 6.576 & 4.313 & 2.712 & 3.904 & 5.136 \\
\hline$-5 \%$ & 1.868 & 2.077 & 5.096 & 6.766 & 3.927 & 2.908 & 3.859 & 5.379 \\
\hline$-10 \%$ & 1.463 & 2.259 & 4.955 & 6.974 & 3.469 & 3.235 & 3.810 & 5.662 \\
\hline$-15 \%$ & 1.671 & 2.491 & 4.837 & 7.286 & 2.951 & 3.643 & 3.738 & 5.969 \\
\hline$-20 \%$ & 2.310 & 2.811 & 4.724 & 7.647 & 2.388 & 4.101 & 3.657 & 6.334 \\
\hline$-25 \%$ & 3.139 & 3.301 & 4.638 & 8.021 & 1.952 & 4.625 & 3.549 & 6.788 \\
\hline
\end{tabular}

IABC algorithm are compared with the BGA [5], RGA [5], and HPSOCFA [5]:

$$
\begin{gathered}
\text { ITAE }=\sum_{i=1}^{4} \int_{0}^{t_{\text {sim }}}\left|\mathrm{ACE}_{i}(t)\right| d t \\
\mathrm{FD}=\frac{\sum_{i=1}^{4} 0.1 \times\left(\left(\mathrm{OS}_{i} \times 100\right)^{2}+\left(\mathrm{US}_{i} \times 5\right)^{2}+\left(T_{S, i}\right)^{2}\right)}{4} .
\end{gathered}
$$

In order to compare the IABC algorithm with the BGA [5], RGA [5], and HPSOCFA [5], the simulation results for $+25 \%$ and $0 \%$ change of parameters of the four-area restructure were shown in Figures 8 and 9, respectively. The simulation was carried out for serial number 1 in scenario I from Case 2. For serial number 2 in scenario II from Case 2, the simulation results with $0 \%$ change of parameters of the four-area restructure for the IABC algorithm, BGA [5], RGA [5], and HPSOCFA [5] were shown in Figure 10. It is observed that the proposed method 


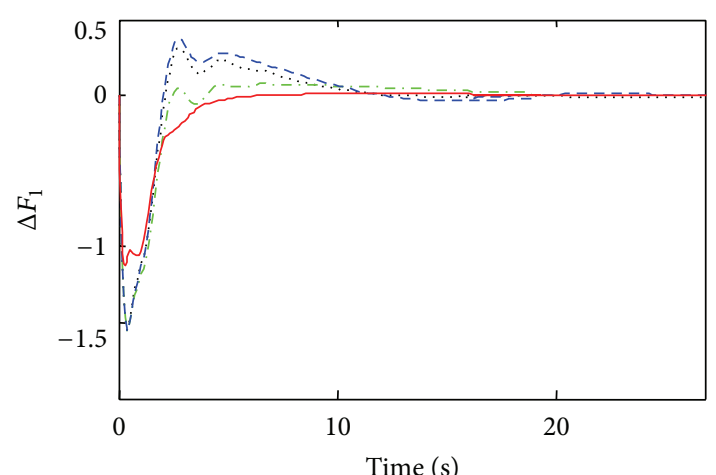

(a)

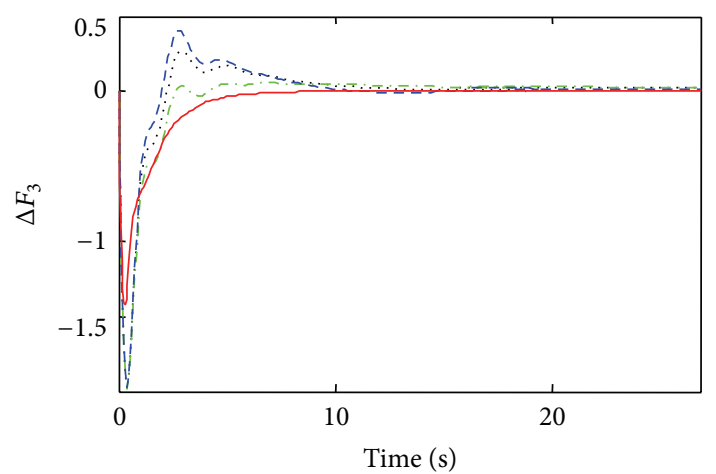

(c)

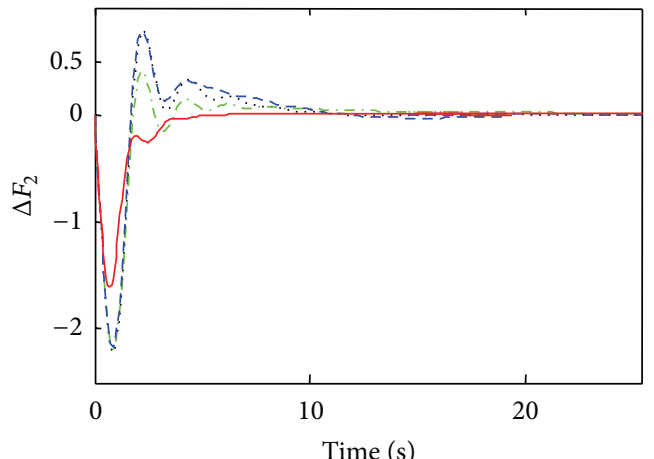

(b)

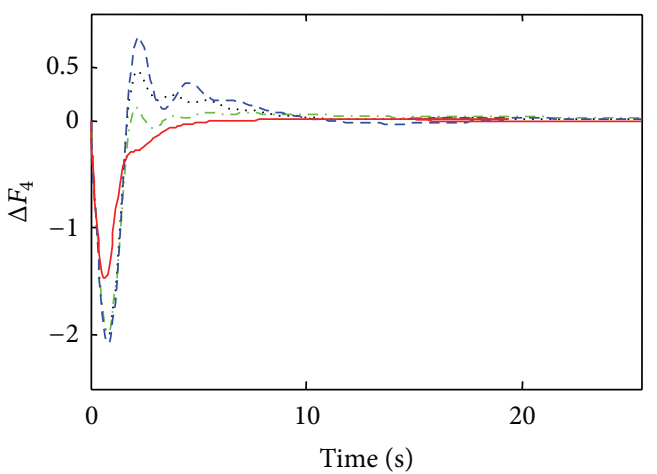

(d)

Figure 9: Deviation of frequency; (a) area 1, (b) area 2, (c) area 3, and (d) area 4 for $+0 \%$ change of parameters; Solid (IABC), Dashed (HPSOCFA), Dashed Dotted (RGA), and Dotted (BGA).

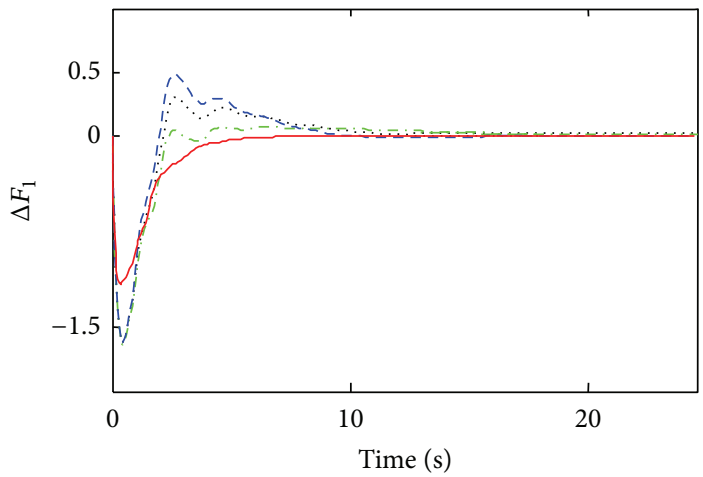

(a)

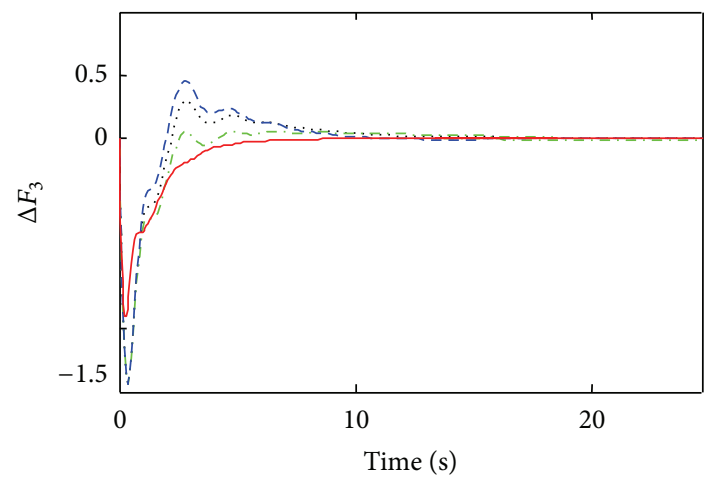

(c)

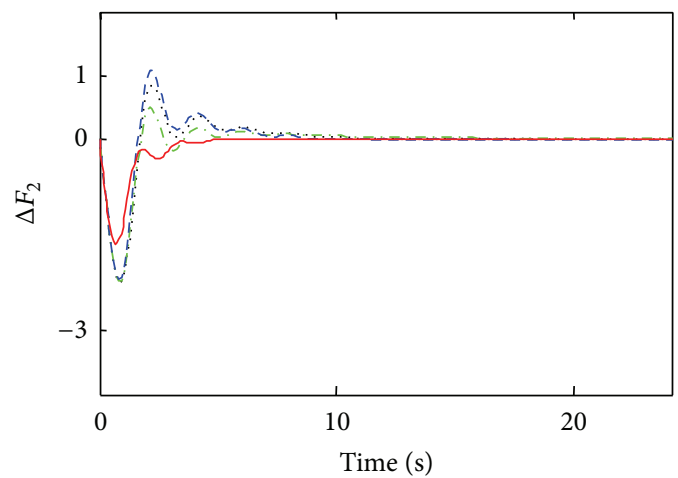

(b)

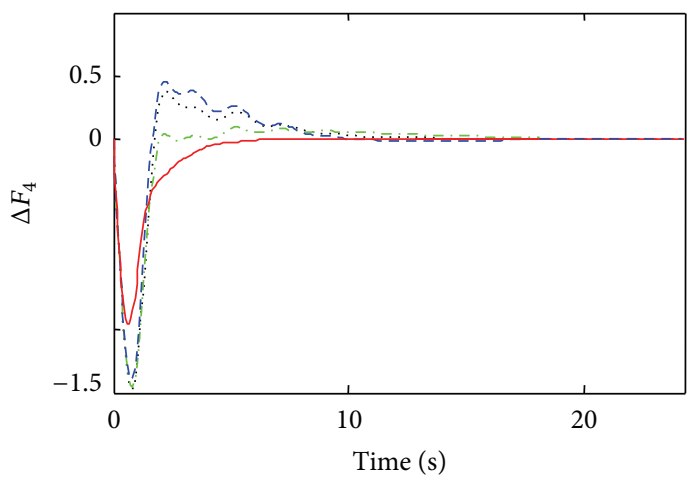

(d)

FIGURE 10: Deviation of frequency; (a) area 1, (b) area 2, (c) area 3, and (d) area 4 for $+0 \%$ change of parameters; Solid (IABC), Dashed (HPSOCFA), Dashed Dotted (RGA), and Dotted (BGA). 


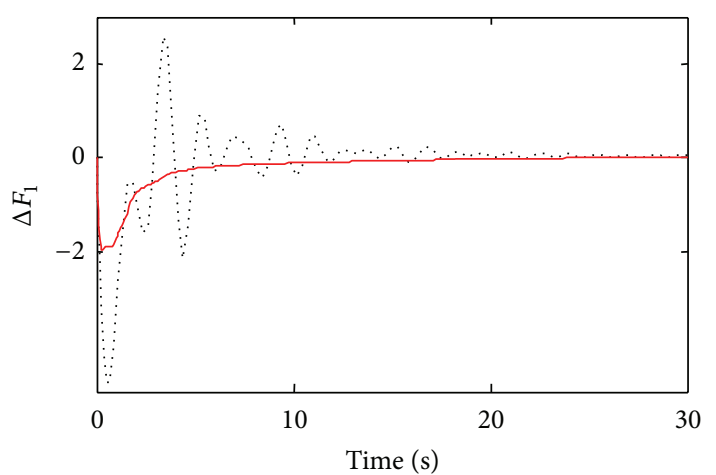

(a)

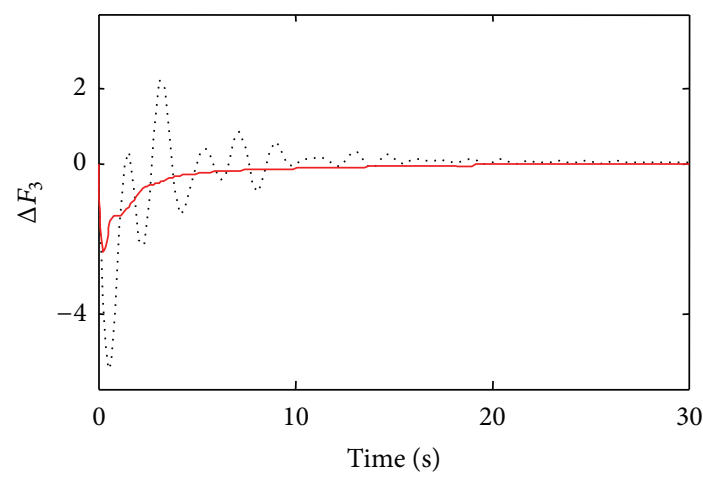

(c)

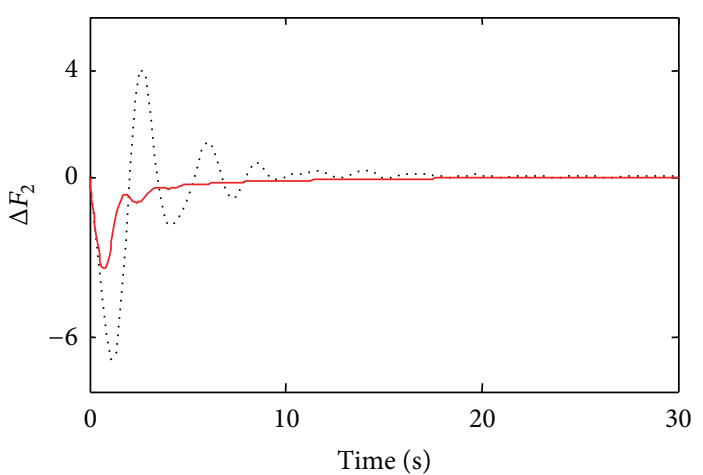

(b)

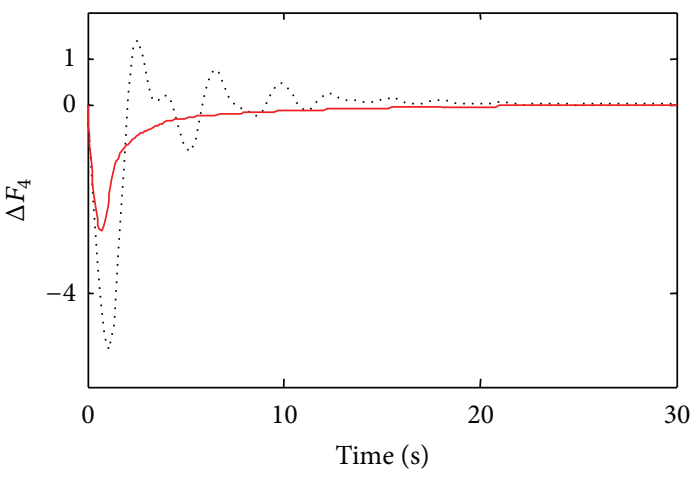

(d)

FIGURE 11: Deviation of frequency; (a) area 1, (b) area 2, (c) area 3, and (d) area 4 for nominal of parameters; Solid (IABC) and Dotted (classical).

achieves better damping for frequency deviations in all the four-areas.

Scenario II. In order to carry out this scenario we make some assumption. The basic assumption of this method is about DPM matrix where all the DISCOs contract with the GENCOs for power as per the following DPM:

$$
\mathrm{DPM}=\left[\begin{array}{llllllll}
0.20 & 0.30 & 0.10 & 0.10 & 0.10 & 0.10 & 0.00 & 0.00 \\
0.40 & 0.30 & 0.10 & 0.20 & 0.10 & 0.10 & 0.00 & 0.00 \\
0.10 & 0.10 & 0.30 & 0.20 & 0.00 & 0.10 & 0.10 & 0.10 \\
0.10 & 0.10 & 0.10 & 0.10 & 0.20 & 0.20 & 0.10 & 0.10 \\
0.10 & 0.10 & 0.10 & 0.10 & 0.20 & 0.20 & 0.10 & 0.10 \\
0.10 & 0.10 & 0.10 & 0.10 & 0.20 & 0.20 & 0.20 & 0.10 \\
0.00 & 0.00 & 0.10 & 0.10 & 0.10 & 0.00 & 0.20 & 0.30 \\
0.00 & 0.00 & 0.10 & 0.10 & 0.10 & 0.10 & 0.30 & 0.30
\end{array}\right]
$$

The other data is similar to the old scenario from Case 2. In addition, the disturbance of the area is $\mathrm{dP}_{1}=5 \%, \mathrm{dP}_{2}=$ $5 \%, \mathrm{dP}_{3}=5 \%$, and $\mathrm{dP}_{4}=5 \%$. The results of the proposed controller based on IABC algorithm are compared with classical controller. Figure 11 shows deviation of frequency for all areas in nominal load. The optimized parameters of PID controller were given in Table 4 for serial number 2 .

\section{Conclusion}

In this paper, an Interactive Artificial Bee Colony (IABC) Optimization based fuzzy (IABCF) to tune optimal gains of a Robust Proportional Integral Derivative (RPID) controller was proposed and also a thorough coordinated application was discussed and investigated for a multiarea restructure in two- and four-area power systems. AGC provides a relatively simple, yet extremely effective, method of adjusting generation to minimize frequency deviations and regulate tieline flows. This important role will continue in restructured electricity markets. A key concept in the work here is that of the "DISCO Participation Matrix" (DPM). The DPM provides a compact yet precise way of summarizing bilateral contractual arrangements. The modeling of AGC in a restructured environment must take account of the information flow relating to bilateral contracts. Clearly, contracts must be communicated between DISCOs and GENCOs. As demonstrated here, it is also important that information regarding contracts is taken into account in establishing/adjusting the tie-line set points. The effectiveness of the proposed method has been tested on a two-area and four-area restructured power system with considered nonlinear power system for a wide range of load demands and disturbances under different operating conditions. Compared with PSO, GA, and classical controller in term of ITAE and FD, the IABC demonstrates its superiority over computational complexity, success rates, and solution quality. 
TABLE 6: ITAE and FD in serial number 2 for scenario I in Case 2.

\begin{tabular}{lcccccccc}
\hline \multirow{2}{*}{ Change of parameters } & \multicolumn{2}{c}{ HBMO } & \multicolumn{2}{c}{ HPSOCFA } & \multicolumn{2}{c}{ RGA } & \multicolumn{2}{c}{ BGA } \\
& ITAE & FD & ITAE & FD & ITAE & FD & ITAE & FD \\
\hline $25 \%$ & 3.579 & 1.182 & 3.732 & 6.679 & 4.995 & 2.799 & 3.828 \\
$20 \%$ & 3.223 & 1.215 & 3.707 & 6.683 & 4.849 & 2.785 & 3.833 \\
$15 \%$ & 2.826 & 1.248 & 3.675 & 6.724 & 4.659 & 2.711 & 3.836 & 4.708 \\
$10 \%$ & 2.383 & 1.282 & 3.623 & 6.790 & 4.421 & 2.664 & 3.851 & 4.847 \\
$5 \%$ & 1.897 & 1.319 & 3.560 & 6.938 & 4.138 & 2.767 & 3.838 & 5.019 \\
Nominal & $\mathbf{1 . 4 0 6}$ & $\mathbf{1 . 3 6 3}$ & $\mathbf{3 . 4 7 9}$ & $\mathbf{7 . 1 3 8}$ & $\mathbf{3 . 8 0 7}$ & $\mathbf{2 . 8 5 5}$ & $\mathbf{3 . 8 4 1}$ & $\mathbf{5 . 2 3 8}$ \\
$-5 \%$ & 1.268 & 1.408 & 3.385 & 7.409 & 3.419 & 3.085 & 3.803 & 5.527 \\
$-10 \%$ & 1.858 & 1.457 & 3.289 & 7.735 & 2.971 & 3.404 & 3.766 \\
$-15 \%$ & 2.508 & 1.514 & 3.211 & 8.120 & 2.464 & 3.832 & 3.696 \\
$-20 \%$ & 3.237 & 1.647 & 3.179 & 8.521 & 1.987 & 4.323 & 3.601 \\
$-25 \%$ & 3.929 & 1.810 & 3.203 & 9.012 & 1.930 & 4.957 & 6.231 \\
\hline
\end{tabular}

TABLE 7: Four area data.

\begin{tabular}{|c|c|c|c|c|}
\hline Name of the parameter & Area 1 & Area 2 & Area 3 & Area 4 \\
\hline Governor regulation, $R(\mathrm{~Hz} / \mathrm{pu})$ & 2.4 & 2.2 & 2.5 & 2.3 \\
\hline Governor time constant, $T_{g}(\mathrm{~s})$ & 0.08 & 0.078 & 0.081 & 0.082 \\
\hline Nonreheat time constant, $T_{t}(\mathrm{~s})$ & 0.3 & 0.5 & 0.7 & 0.4 \\
\hline Reheat time constant, $T_{r}(\mathrm{~s})$ & 4.2 & 4.1 & 4.0 & 4.3 \\
\hline Reheat parameter, $c$ & 0.34 & 0.31 & 0.32 & 0.33 \\
\hline Power system gain constant, $K_{p}(\mathrm{~Hz} / \mathrm{pu})$ & 120 & 115 & 118 & 116 \\
\hline Power system time constant, $t_{p}(\mathrm{~s})$ & $10-20-30$ & 20 & 10 & 20 \\
\hline Frequency bias coefficient, $b$ & $0.125-0.275-0.425$ & 0.125 & 0.275 & 0.125 \\
\hline \multicolumn{3}{|c|}{ Tie-line synchronizing coefficient between areas 1 and $2, T_{12}$} & \multicolumn{2}{|c|}{$0.145-0.345-0.545$} \\
\hline \multicolumn{3}{|c|}{ Tie-line synchronizing coefficient between areas 2 and $4, T_{24}$} & \multicolumn{2}{|c|}{0.145} \\
\hline \multicolumn{3}{|c|}{ Tie-line synchronizing coefficient between areas 4 and $3, T_{43}$} & \multicolumn{2}{|c|}{0.345} \\
\hline \multicolumn{3}{|c|}{ Tie-line synchronizing coefficient between areas 2 and $3, T_{23}$} & \multicolumn{2}{|c|}{0.145} \\
\hline \multicolumn{3}{|c|}{ Tie-line synchronizing coefficient between areas 3 and $1, T_{31}$} & \multicolumn{2}{|c|}{$0.145-0.345-0.545$} \\
\hline
\end{tabular}

\section{Nomenclature}

$T_{T}$ : Turbine time constant

$T_{H}$ : Governor time constant

y: $\quad$ Area interface

$\Delta: \quad$ Deviation from nominal value

$P_{\mathrm{UL} j i}$ : Uncontracted demand of DISCO $j$ in area $i$

$P_{m, j i}$ : Power generation of GENCO $j$ in area $i$

$P_{\text {tie }}$ : Net tie-line power flow turbine power

$P_{L j i}$ : Contracted demand of DISCO $j$ in area $i$

$\zeta$ : $\quad$ Scheduled power tie-line power flow

deviation (DPtie, sch.)

apf: ACE participation factor

$P_{d}: \quad$ Area load disturbance

$P_{\text {Loc }}$ : Total local demand.

\section{References}

[1] A. Nargelas and R. Bikulcius, "Distributed automatic generation control in the conditions of electricity market," Power and Electrical Engineering, vol. 3, no. 4, pp. 43-49, 2001.

[2] H. Bevrani, F. Daneshfar, and T. Hiyama, "A new intelligent agent-based AGC design with real-time application," IEEE
Transactions on Systems, Man, and Cybernetics $C$, vol. 42, no. 6, pp. 994-1002, 2012.

[3] M. Zribi, M. Al-Rashed, and M. Alrifai, "Adaptive decentralized load frequency control of multi area power systems," International Journal of Electrical Power \& Energy Systems, vol. 27, no. 8, pp. 575-583, 2005.

[4] V. Donde, M. A. Pai, and I. A. Hiskens, "Simulation and optimization in an AGC system after deregulation," IEEE Transactions on Power Systems, vol. 16, no. 3, pp. 481-489, 2001.

[5] P. Bhatt, R. Roy, and S. P. Ghoshal, "Optimized multi area AGC simulation in restructured power systems," International Journal of Electrical Power and Energy Systems, vol. 32, no. 4, pp. 311-322, 2010.

[6] A. Ghasemi, M. S. Naderi, and O. Abedinia, "Robust LFC in deregulated environment: fuzzy PID using HBMO," in Proceedings of the 10th International Conference on Environment and Electrical Engineering (EEEIC '11), 2011.

[7] S. Taher, R. Hematti, A. Abdolalipour, and S. H. Tabei, "Optimal decentralized load frequency control using HPSO algorithms in deregulated power systems," American Journal of Applied Sciences, vol. 5, no. 9, pp. 1167-1174, 2008.

[8] E. S. Ali and S. M. Abd-Elazim, "Bacteria foraging optimization algorithm based load frequency controller for interconnected 
power system," Electrical Power and Energy Systems, vol. 33, pp. 633-638, 2011.

[9] P. Aravindan and M. Y. Sanavullah, "Fuzzy logic based automatic frequency control of two area power system with GRC," International Journal of Computational Intelligence Research, vol. 5, no. 1, pp. 37-44, 2009.

[10] E. Yesil, M. Guzelkaya, and I. Eksin, "Self tuning fuzzy PID type load and frequency controller," Energy Conversion and Management, vol. 45, no. 3, pp. 377-390, 2004.

[11] A. Ghasemi, B. Wyns, and O. Abedinia, "Robust fuzzy PSS design using $\mathrm{ABC}$," in Proceedings of the 10th International Conference on Environment and Electrical Engineering (EEEIC '11), 2011.

[12] G. Panda, S. Panda, and C. Ardil, "Automatic generation control of interconnected power system with generation rate constraints by hybrid neuro fuzzy approach," International Journal of Electrical Power \& Energy Systems, vol. 2, no. 1, pp. 13-18, 2009.

[13] S. P. Ghoshal, "Optimizations of PID gains by particle swarm optimizations in fuzzy based automatic generation control," Electric Power Systems Research, vol. 72, no. 3, pp. 203-212, 2004.

[14] D. Karaboga, "An idea based on honey bee swarm for numerical optimization," Technical Report TR06, Erciyes University, Engineering Faculty, Computer Engineering Department, Kayseri, Turkey, 2005.

[15] D. Karaboga and B. Basturk, "A powerful and efficient algorithm for numerical function optimization: artificial bee colony (ABC) algorithm," Journal of Global Optimization, vol. 39, no. 3, pp. 459-471, 2007.

[16] S. L. Sabat, S. K. Udgata, and A. Abraham, "Artificial bee colony algorithm for small signal model parameter extraction of MESFET," Engineering Applications of Artificial Intelligence, vol. 23, no. 5, pp. 689-694, 2010.

[17] P. W. Tsai, J. S. Pan, B. Y. Liao, and S. C. Chu, "Enhanced artificial bee colony optimization," International Journal of Innovative Computing, Information and Control, vol. 5, no. 12, pp. 50815092, 2009.

[18] E. Rashedi, H. Nezamabadi-pour, and S. Saryazdi, "GSA: a gravitational search algorithm," Information Sciences, vol. 179, no. 13, pp. 2232-2248, 2009.

[19] G. A. Gurzadyan, Space Dynamics, Taylor \& Francis, London, UK, 2002.

[20] Y. P. Kuo and T. H. S. Li, "GA-based fuzzy PI/PD controller for automotive active suspension system," IEEE Transactions on Industrial Electronics, vol. 46, no. 6, pp. 1051-1056, 1999.

[21] M. Chadli and T.-M. Guerra, "LMI solution for robust static output feedback control of Takagi-Sugeno fuzzy models," IEEE Transactions on Fuzzy Systems, vol. 20, no. 6, pp. 1160-1165, 2012.

[22] S. Bououden, M. Chadli, S. Filali, and A. El Hajjaji, "Fuzzy model based multivariable predictive control of a variable speed wind turbine: LMI approach," Renewable Energy, vol. 37, no. 1, pp. 434-439, 2012.

[23] A. Ghasemi, H. Shayeghi, and H. Alkhatib, "Robust design of multimachine power system stabilizers using fuzzy gravitational search algorithm," Electrical Power \& Energy Systems, vol. 51, pp. 190-200, 2013.

[24] H. A. Shayanfar, H. Shayeghi, A. Jalili, and M. Sivandian, "A genetic algorithm based AGC of a restructured power system," in Proceedings of the International Conference on Artificial Intelligence, pp. 237-240, Las Vegas, Nev, USA, June 2006. 

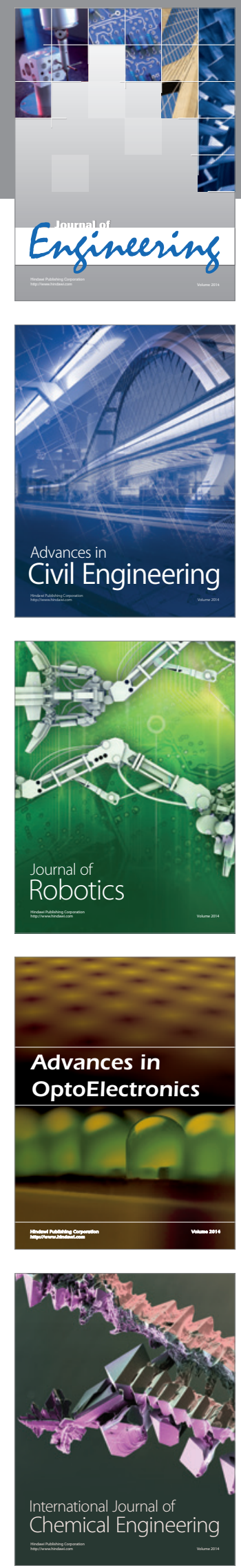

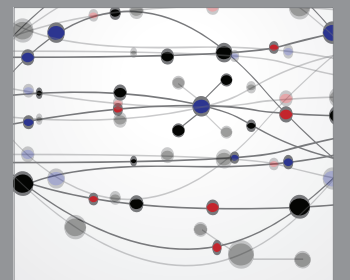

The Scientific World Journal
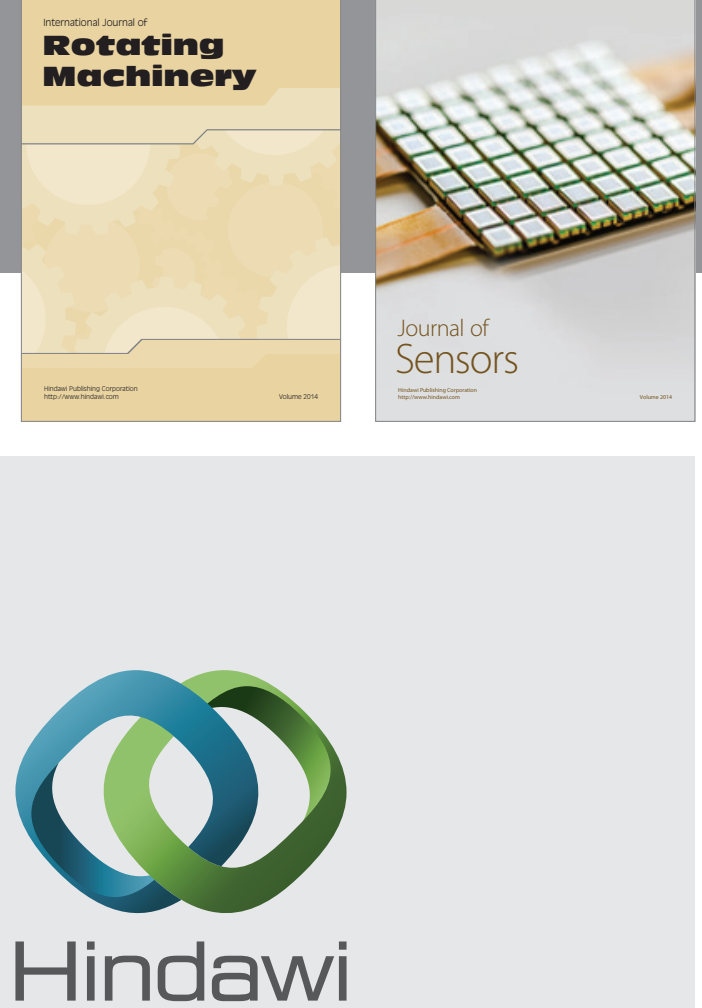

Submit your manuscripts at http://www.hindawi.com
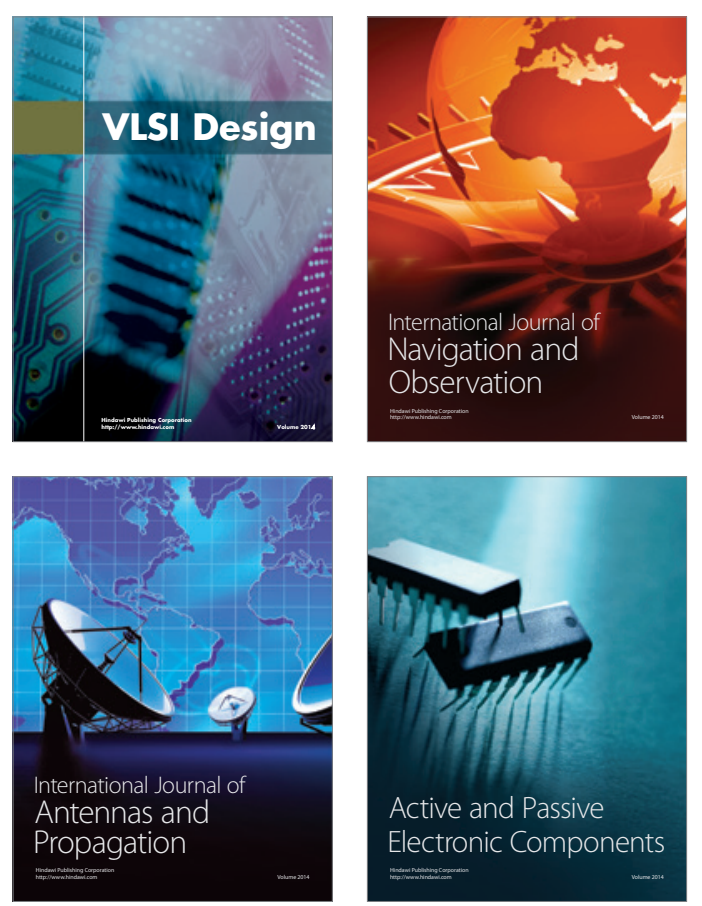
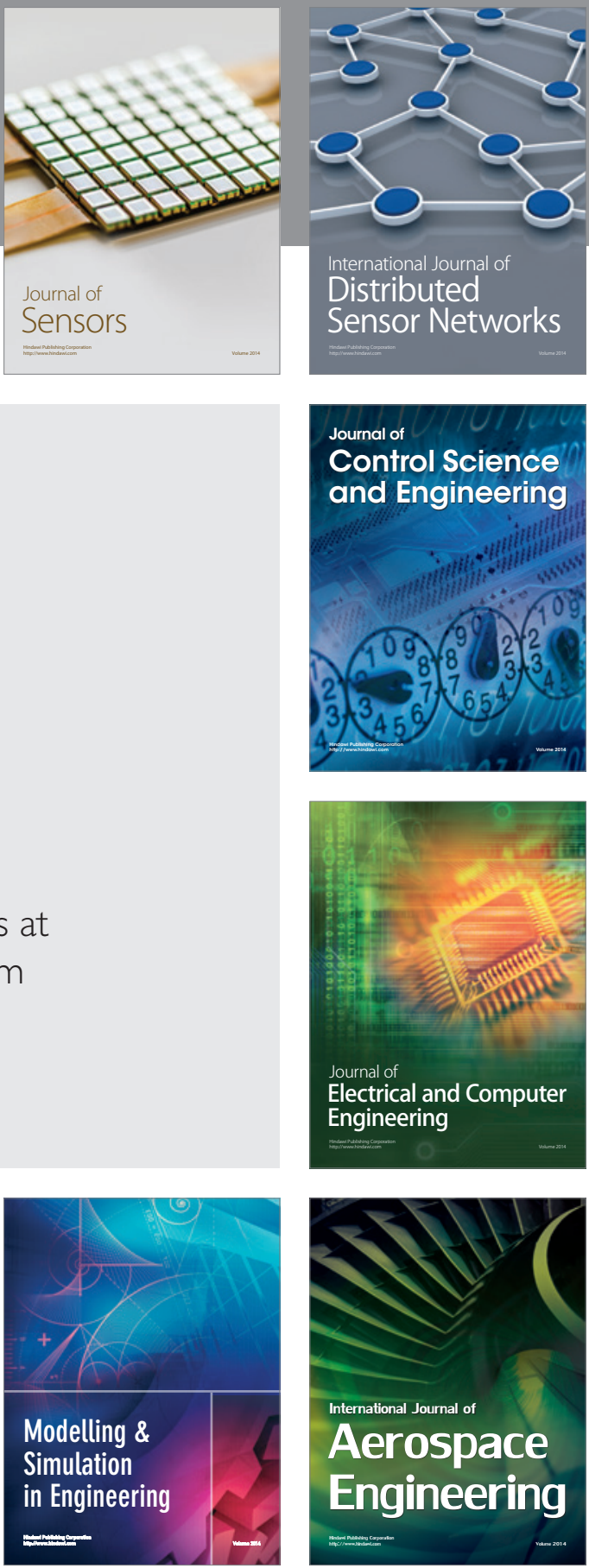

Journal of

Control Science

and Engineering
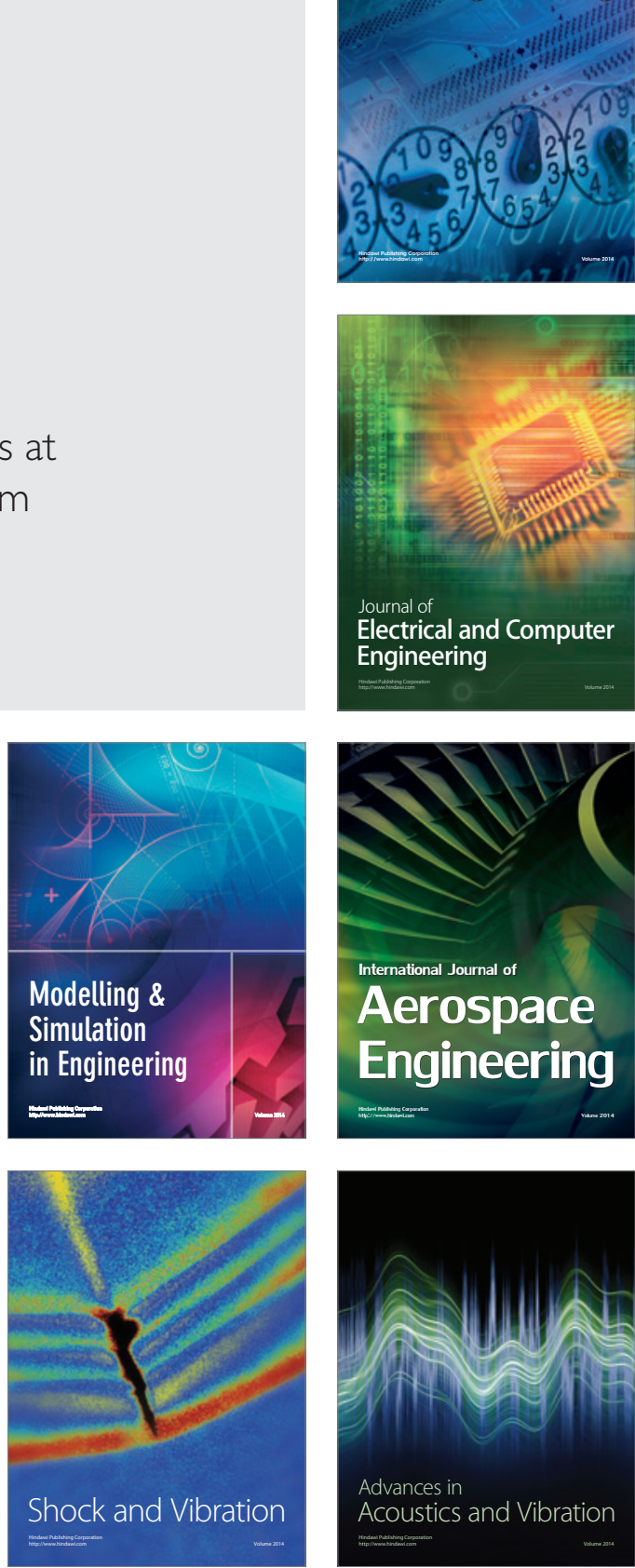